\title{
Mind Body Spirit in the Groups at the 2016 NZAP Conference
}

\section{Margot Solomon (Editor), Virginia Edmond, Amanda Garland, Lynne Holdem, Burke Hunter, Crea Land, Fay Lilian, Jules Morgaine, Claire Virtue}

\author{
Auckland, Wellington, Taranaki, Nelson, Manukau, Hawke’s Bay
}

\begin{abstract}
The editors of Ata: Journal of Psychotherapy Aotearoa New Zealand asked if I (Margot Solomon) would write some reflections on the group experiences at the NZAP conference this year. I invited the small group facilitators to write something of their experience. This paper describes some of what happened and how that has been understood by a few of us that held roles at the conference. I begin by describing the preparation for the conference; this is followed by the reflections from some of the small group facilitators and a representative from the Conference Organising Committee. I then offer my experience and thoughts, and end with a brief discussion of key themes present in what has been written.
\end{abstract}

\section{Waitara}

I tonoa au, a Mākere Solomon, e ngā ētita o te Hautaka Whakaora Hinengaro o Aotearoa kia huri ki te tuhi i ètahi whakahokinga whakaaro mō ngā wheako rōpū i te hui o tenei tau a te NZAP. Nāku i tono atu ngā kaiarataki o ngā rōpū iti kia tuhia mai êtahi wheako ō rātou. Ko ēnei ētahi o ngā whakaāhuatanga o ngā arahanga ake me te huanga ake o te arotau e te tokoiti o mātau i whai wāahi ki ērā mahi i te hui. I tīmatahia e au mai i whakaritenga mō te hui, kātahi ka huri ki ngā whakaatanga mai a ètahi o ngā kaiarataki rōpū iti me ōku whakaaro. Hai whakakapi ka huri ki te whakarāpopoto i ngā matapakitanga o ngā kaupapa matua kua tuhia nei.

Keywords: biculturalism; manaakitanga; matrix; holding; small groups; large groups; spirituality

At the 2016 NZAP conference called "Mind, Body and Spirit: Holistic Psychotherapy" I wrote outlines for the small and large groups. For the small groups I said that the function was to provide a home space for delegates to review their experience of the conference in a safe setting. I made it clear that these groups were not therapy groups - rather, groups of

Solomon, M., Morgaine, J., Holdem, L, Virtue, C., Hunter, B., Garland, A., Land, C., Edmond, V. \& Lilian, F. (2016). Mind body spirit in the groups at the 2016 NZAP Conference. Ata: Journal of Psychotherapy Aotearoa New Zealand, 20(1), 57-72. DOI:10.9791/ajpanz.2016.06 ( ) New Zealand Association of Psychotherapists Inc. 
colleagues coming together to reflect on their experience of the conference. I commented that the common goal was to help create the feeling of being a group; it was hoped and expected that each group would create their own sense of boundedness. I contrasted the large group as a community space with the small group representing the family unit. In the large group conference delegates would have the opportunity to share their experience and to dialogue with each other about what moved them at the conference and with each other. I ended by saying that the large group holds all the conference delegates with their differences and similarities, providing an opportunity to engage in our diversity.

I am not sure we achieved these goals; some would say we did but everybody has a different experience. In the large group the clearest division is generally between those who speak and those who remain silent. I had a fantasy of inviting all those who were there to write something - and then to reflect on that. Perhaps another time. In this article I bring all of NZAP, the large group, through my eyes and the small groups through the eyes of Burke, Virginia, Amanda, Fay, Crea, Lynne, Claire, and Jules.

\section{Preparation, Margot Solomon}

Sometime in 2015 I was invited to facilitate the large group at the 2016 NZAP conference. I met briefly with the conference committee at a workshop in Wellington in July 2015. I was clear that we needed to have small groups preceeding the large group in order to give people a chance in an intimate space to have their say, to find their voice, to hear others, and to gain a sense of connectedness, especially for those who were newish to NZAP conferences. The conference committee was enthusiastic about this idea. I took on to find the group leaders, asking people who I knew had experience of working with groups. I set up a structure where everybody was supported in their roles. Small group leaders met with me and one of the conference committee members three times: before the first small group, in between the two small groups, and after all groups were over. This provided holding behind the scenes for the small group leaders. It also touched me into the processes in the small groups and their concerns, and helped hold the large groups.

My instructions for the small group leaders were simple: This is a chance for conference delegates to reflect together on their experience of the conference. Each voice matters. There is no goal to agree; more to find a way to be together with who they each are during this time and to use the small group as a secure base.While the small group leaders were meeting with their small groups, I met with the conference committee to give them a chance to reflect on where they were up to.

\section{Reflections From Some of the Small Group Facilitators}

\section{Small group 1, Burke Hunter}

The group was slow to gather and find where to go. Some wanted to stay in the sunshine and not move. We did move and for me there was excited, laughing energy. On the two occasions that we met we were scattered in mind and body and at first couldn't find our room. When we did there was a general consensus to move outdoors and sit in the sun. It seemed a release 
from the seriousness after the keynote talks. One person described it as the facilitator needing to catch us as the runaway train that we initially were. Having a mindfulness moment at the start helped us to deepen and share our thoughts with each other.

One of our members raised a question about our spirituality, as one of the keynote speakers had raised the challenge of the lack of spirituality for those who are not Indigenous. We acknowledged that we had our own spiritual connections but that they tended to be personal and that it was difficult to put that forward into the conference gatherings in the way Māori spirituality is represented. It was a relief however, to be dropping into this topic as there was such strong Māori spiritual presence at the conference and it was good to share something of our own with each other.

After we settled we spoke about our spirituality and cultural rituals both as individuals and as an association. We acknowledged that the rituals of NZAP conferences are known to those who've attended past conferences. These people hold our cultural memory. It was mentioned that in Māori culture, at significant times, for example, during conflict, people will speak the remembered words of a revered elder. We acknowledged that we do not have that in non-Māori culture. I said that Roy gathering information from people of NZAP would one day provide us with the words of wisdom of our elders. It was put to Roy that when his book comes out it should be read actively, like a workbook. The rituals of beginning by lighting the candle and acknowledging the rope that binds us together in our association and the singing bowl that came from the Christchurch conference need to be spoken about so that they become life-giving taonga, the treasures of our association.

The feeling in the group was warm and spontaneous. The group felt it was valuable to have small groups where everyone has an opportunity to speak.

\section{Small group 5, Virginia Edmond}

When I received the list of participants who had been allocated to my group the process immediately became more complex than it had previously seemed. Being a group facilitator of a group of peers in a community you belong to is a different thing to doing it with people you do not know or who are clients. I wondered about those who did not come at all or who decided to go to a different group and how the grouping and facilitator might have affected those decisions.

The group met for the first time in a very cold room and we began by introducing ourselves to each other. I saw my role as holding the group, watching the time, and suggesting the introductions at the beginning. I participated in the discussions but did not intervene to direct anything. Discussion was a little tentative and more like people stating views than dialogue. The second day was quite different and dialogue did occur, stimulated by the lively and contentious panel discussion on Friday morning but also by the group developing more safety I guess. Three group members did not return on the second day and I wondered if the group had not provided enough safety or the possibility of belonging. Had we or I failed those people somehow? Had the group not been engaging or interesting enough for them? Briefly, at the beginning of the day two group, there was the emptiness of having been left and not knowing why before we regrouped and engaged as the group we now were.

I thought situating the small groups just before the large group was very important and contributed to engagement in the process of the large group. The small group provided a 
more manageable place to express some of what people were thinking and feeling and some could then go on to say it in the larger context thus making the large group livelier. I thought the large group on the second day felt more alive than on the first day in a similar way as my small group did. We seemed more ready to grapple with issues and ideas and less afraid to express difference. I have wondered where and how the previous Napier group experience lies in the unconscious of the large group and how the telling off in the first large group fits with that. I also wonder if it would have been useful to have a final small group on Saturday morning and run Forum as a large group to follow.

I have heard some people say since the conference that they do not understand the purpose of the large group so I wonder if there is a need to keep saying something about this as new members come to conferences.

\section{Small group 7, Amanda Garland}

At the 1998 NZAP conference titled "Boundaries, Space, Structure and Creativity” we began the continuing model of having small and large groups. The idea of psychoanalytically-run groups was to both introduce and offer a way of working together. We offered a framework for thinking about and understanding some of the issues within NZAP, including our Treaty partnership, issues of employment, and models of psychotherapy practice in New Zealand Aotearoa. Most specifically, to meet and learn about each other both as individuals and as a group, indeed as an organisation, to discover and form a stronger sense about who we are and where we were going.

The whole of the 1998 conference was embedded in offering an experience of being a member of a small group and the large group, with the aim of moving toward some cohesion of the whole organisation of NZAP. This pattern of small and large groups has followed, in part, for the past $1 \delta$ years. The most consistent "place" has been the large group as there have been conferences with and without the small groups. Something of the steady continuity and holding of the frame by the facilitators and the group mind of the large group is visceral in the room. The space is held and known enough to retain its structure, its skeleton, its "bearing", so something can be born, with everyone gathered together, however difficult, anxious-making, funny, and moving the experience. Indeed, "visceral" means "affecting the viscera or bowels, regarded as the seat of emotion, pertaining to or touching deeply inward feelings and is from "viscera": internal organs, soft contents of the principle cavities of the body, especially the internal organs of the trunk, the entrails or bowels, together with the heart, liver and lungs, the interior the inner parts" ("Visceral", 1978).

The large group is one of the NZAP conference rituals and has retained its potency and voice. The small group experience has not carried through so consistently, perhaps by not being continued throughout each conference, and maybe by too few group meetings per conference, so its capacity as a limb to this torso is truncated. It certainly does some massaging for the large group, but also requires consistency of attendance throughout to be of more effective use.

What was clearly present in its absence was a sense of the severed parts, the lost, the forgotten or repressed parts, of the whole body and mind of NZAP and the binding sense of who we are and where we are going. Have we lost our mana as taught to us by Tama Iti in his TED talk presented as part of the conference? (Iti, 2015). 
In 1998 we began a conversation from which we have, maybe, lost our way, and we need our elders and those who hold the stories to re-member ourselves: starting with giving time to the nurturing, the careful and attentive appreciation within our own association.

I will end with a quote from the final paragraph of Mosse and Roberts' chapter in The Unconscious at Work:

Finally, having determined what needs to be said to whom, there remains the question of who will say it. Unless individuals can be empowered to speak, whether on their own behalf or on behalf of the group, the threatening conditions are unlikely to change. Denying the reality of internal differences is disempowering: neither internal nor external negotiation is then possible. In many cases even the capacity to think will be lost. Yet now, more than ever, it is imperative to retain the capacity to think and act effectively under threat. If anxiety can be contained, then what needs to be talked about can be named, and some effectiveness recovered.(1994, p. 155)

\title{
Small group 8, Fay Lilian
}

Some questioning of leadership began as we gathered outside and continued as the group came together for the first session; how facilitators got chosen was not asked or answered.

The group responded to the keynote speaker's challenge about the absence of Pākehā spirituality. When invited to bring body and spirit, as well as mind, into our reflections the group settled, got acquainted with each other, and softened. Some folk became very concerned that a praying mantis by the facilitator's feet might be squashed; it was quickly and carefully moved outside. This prayerful symbol of spirituality could not remain in our small community, lest it be trampled underfoot.

In the second session the theme of suicidal ideation continued from the keynote talk. There seemed to be a hunger for answers, though most solutions could not be swallowed. Were we feeding ourselves well enough to survive this work?

We pondered our sensitivity to criticism of our lack of sensitivity to Maōri protocol. Our small group was a microcosm of the large group, and reflected its diversities. The sessions enabled us to engage kanohi ki te kanohi (face to face); to all feel, think, and speak something of our experiences.

\section{Small group 9, Crea Land}

\author{
Holding open space \\ We sit \\ We think \\ We feel \\ We allow our internal worlds to emerge \\ Sometimes greatly...sometimes only a wee bit \\ We do what we can. \\ We invite our own opening to spaces within ourselves \\ We consider, and decide, on some level \\ Will I let this be seen \\ Can I let this be seen.
}


True vulnerability enables the possibility of connecting

Human to human

Mind to mind

Heart to heart

Spirit to spirit

Soul to Soul...

And here----we love.

\section{Small group 10, Lynne Holdem}

Our small group was allocated the dining hall and we were unable to hear each other because of the joyful noise made by ngā ringawera (the cooks in the kitchen). We looked for an alternative home and decided on the grass square outside the meeting room. This brought us in close proximity to Māori healers who were massaging and working with the mind-bodyspirit of NZAP members. This provided a nurturing backdrop to our small group and also an experience of being alongside, and sharing space with, an alternative healing world view.

These experiences, difficulty in hearing others and learning how to be alongside a very different view of therapy and how healing takes place, were echoes of the themes and challenges of the conference as a whole.

The small group helped me hold and understand some of the eruptions and emotional disturbances in the large group through the refractions and reflections of the other group members. Contributions of other minds, quite different from my own perceptions, helped construct a larger and more complex understanding of the conference, especially the large group, the bicultural experience group, and the panel discussion.

Small groups appear to be a place where we are able to open to another's picture of the world with, perhaps, less defence and reactivity than may occur in a large group. This really helped me digest the, at times, passionate and challenging moments of Napier's 2016 conference.

It seems to me that if conflict and concern arise out of this that would be a good thing given the degree to which opinions about the bicultural nature of NZAP and its growth in this direction have not been expressed, have been withheld for the reason, presumably, of Pākehā fear of confrontation, being seen as racist, or need to be polite. I feel that it is so important that our association does not censure conflict or embarrassing differences or cultural misunderstandings but endeavours to think about them and work through them.

\section{Small group 11, Claire Virtue}

To have space to reflect and contribute within the three-day NZAP conference was invaluable as a group member in the large group. To participate in the large group required courage, clarity, and goodwill to self and other. The themes that many spoke to in the large group were spirituality, racism, and the bicultural journey of NZAP. Nine years ago in Napier the journey of NZAP's bicultural partnership with Waka Oranga began. Now nine years later many of those in the large group spoke of that difficult and painful time and where NZAP is now. These themes were emotional. The emotion experienced by many was at times beyond words.

In those moments, for me, a void emerged where an annihilatory silence threatened to swallow the whole group, rendering any connected experience impossible. Once the silence 
was named a bridge was made for others to speak and make themselves visible.

The small group experience was a space for people to speak their process. Many in my group related their process to the themes emerging from the keynote and plenary speakers' addresses. The group I was part of was a mix of cultural identities. Some spoke of being outside the dominant European/Pākehā culture. The experience of being on the margins echoed in the morning and throughout the whole conference as a constant theme in the small group, yet there was also personal sharing of being touched spiritually, particularly by the opening of Charlotte Mildon's address where karakia chanting with stones drew tears from me and others. As one participant said in our small group, "You got touched by the holy spirit." Maybe so. It seemed many were touched by spirit and pain simultaneously.

David Tacey's challenge to the Pākehā members of the conference that he could not see any expression of Pākehā spirituality there was met with anger and disbelief. In the small group I was in we were reminded by one person that David did ask in the previous morning what or how do Pākehā express their spirituality? Apparently he was met with silence. I found it very interesting that I could not remember David asking this question, yet others in my group did indeed remember. Perhaps the question was too big to answer, or is it too difficult for an individual to expose their spiritual context and meaning? In addition to not remembering this question I wondered about the unconscious process at work; in terms of who could remember the questions and who could not?

There was also concern expressed about David's wellbeing after he received such strong responses. Yet it was noted that he was not going to be present for further discussion in the afternoon. I was left with a question for David and for the Pākehā members of the conference: Is there space for spiritual expression in all forms including Māori at future conferences? David spoke of the question he was asked by Indigenous Australians: What is your sacred story? This question hung in the air.

Therapy is speaking and holding sacred stories, and the large and small groups were places where sacred stories did emerge. Do we recognise these stories as sacred when they are spoken? How to recognise the spirit in all of us is a question that David's question left me with. It is too easy to assume, to project. Perhaps it is time for a "coming out" process, for the spiritual in psychotherapy to emerge more fully for those of us in the dominant culture known as Pākehā.

\section{Representative from Conference Organising Committee, Jules Morgaine}

As an organising committee our vision for this conference was to offer a bicultural experience to participants. As such we hosted the conference at Te Ara O Tāwhaki Marae and, in doing so, embedded tikanga Māori in our processes.

Central to this is manaakitanga, the caring for ourselves and each other, alongside caring for our visitors. As a small organising group of six we were able to attend to this well leading up to the conference. We worked collectively to support each other in the planning and preparation and had a lot of fun in doing so.

Manaakitanga is so much more than hospitality, generosity, and care. It also asks of us to care for the mana of our esteemed guests whom we invite to contribute. It is the little things that matter - a chair at the front, the opportunity to present products, protection when on difficult ground, a warm holding within the space, public acknowledgement of their 
contribution, attendance to small details (like data projectors that do not turn off!).

The pressure on our small group increased dramatically once the conference began. Now there were so many more people to care for alongside a myriad of tasks to attend to and some unexpected physical constraints created by the environment and a lack of care by Eastern Institute of Technology (the venue) for us as visitors. As a group we became fragmented as we each attempted to manage these challenges.

The small group process gave us a valuable opportunity to come together and process the pain we felt in not being able to meet our ideal, especially for our invited guests. Amidst the demands of "doing" it was a small oasis where we could attend to our "being", our individual and collective responses to the struggles we were having, a place for tears and being heard. It was this emotional care for each other (manaakitanga) that supported us in being able to care for our guests.

It would have been very easy to use this time in a task-focused manner as there was so much to attend to. I want to acknowledge Margot in her recognition of our need for this emotional support and, in doing so, holding a space where it was safe to give voice to our struggles and reconnect with the unity of our vision. It was invaluable to have this time.

Both the small group and large group processes enabled me/us to more deeply comprehend the enormity of manaakitanga and what it actually requires to provide this on a large scale. I am reminded of the saying "it takes a community to raise a child". So too, it takes a large extended community to meet the challenge of hosting a large conference biculturally. I for one had underestimated this.

Manaakitanga ideally leaves guests remembering the gathering with fondness and gratitude. For many this was the case. Our small group process continues as we attend to the hurts and ruptures that occurred for some. At least we now have the space to do this with great care and love for each other.

\section{Large Group, Margot Solomon}

On Thursday when the large group started there were empty chairs; perhaps we overestimated who would come. The chairs were not set up in a perfect circle but were set up to fit the space. I stood, listened, watched, breathed into my body, readying myself until the moment for me to speak arrived. I noticed that the voices quietened gradually, and everybody was ready together like a large organism taking a breath. I opened the space by inviting them to speak when they felt the urge, letting them know they did not need to say a lot, this was not the space for speeches but a space for dialogue. It helped if people spoke to each other.

The questions that came early on were where is the Pākehā spirituality? And from Māori, what was it like for Pākehā and tau iwi that there was such a strong Māori focus in the conference so far? What happened after Charlotte Mildon finished speaking when there was a silence? One of the responses was that there was a fear of conflict. Conflict leads to dialogue I thought to myself, and then somebody said that. But in this space it has not always.

What came next was predictable, the group remembered that here in Napier nine years ago there had been a painful collision of two value systems, the Western approach to the large group and the Māori hui. Here in 2016 there was an echo in the group of the pain of nine years ago, even for some a wondering about the meaningfulness of some absent 
members. Somebody else said it was the birth of Waka Oranga and another voice added, "Look at where we have got to, with one of our own leading the large group. There has been significant growth.”

Gradually the group slipped into a miasmic comfort as it congratulated itself on how well NZAP was doing. On the other hand, I became increasingly uncomfortable and eventually I said I could feel a tension between holding the group and giving the group a prod. Chomsky said in the documentary film Notes to Eternity (Cordery, 2014) that he is interested in the parameters of thinkable thoughts, in other words, what can and cannot be said. There is plenty that cannot be said, or even thought about or remembered in a large group setting. This can be deadening if not addressed.

There was a passionate exchange amongst people who work in the medical profession and hospital system. They reminded us of what they hold; the tension between the medical psychotherapeutic models, and what it is like attempting to bring change in the medical environment. Out of this arose some questions about how we bring together our different frames of reference, and, in particular, here at the conference, how to hold the psychotherapy frame and the marae tikanga. Being-with, working alongside was the main suggestion. I thought of the story Haare Williams told in the wharenui when he was reflecting on his connection to Evan Sherrard. He described an event from the Waitangi conference where the day started with a karakia at the flagpole. What happened was a natural back and forth between Haare and Evan, partly in Te Reo, partly in English. I remembered that experience as a true being-with. It also reflects what Russell Waetford and I embarked on in 2004 when we started community kōrero at Auckland University of Technology.

At the end of the first session, our Mãori kuia said that we did not seem to understand that it was disrespectful to wear jeans to a powwiri. She had been with us for nine years and she was still working to forgive us for what happened with Haare nine years ago, however, she had made a commitment to us.

The second session started in a livelier manner. This time we had not put out enough chairs which meant latecomers were somewhat disruptive. However, it did feel as if more people were engaged. I can only speculate that there was more to say, or people felt safer and more a part of the overall process of the conference and what it offered.

As predicted by one of our senior members, the keynote speaker David Tacey was discussed in the second session. David had challenged us in the panel session on Friday morning with a question: What is your sacred story? He felt there was a vacuum in the spirituality of Pākehā New Zealanders. The question was upsetting and stimulating. $\mathrm{He}$ thought there needed to be a corresponding renaissance in the non-Māori group for the Māori renaissance to be successful. Unfortunately, he did not stay with us for the whole of the conference, or even for a whole day, and so he missed the rituals and ways of making meaning of our experience that have evolved in NZAP and are thus a part of our spiritual practice as a community. I think he also failed to understand the way that Pākehā have needed to stand aside to leave space for Māori to claim their place as first people here in Aotearoa, recognising the colonising impact and the loss of power that this has meant for Māori. There is such a potpourri of ways of being spiritual, so when we come together we have developed rituals with the candle, with waiata in the large group, and, yes, we have adopted some Māori ways. When I have travelled out of New Zealand I have become aware 
how much our language has been influenced by Te Reo. It is a part of entering the fabric of Aotearoa as our home. The large group as a part of our culture began when Louise de Lambert and others initiated its inclusion at NZAP psychotherapy conferences back in 1998. The next time a large group was held at a conference was 2004 in Auckland when I invited Teresa von Sommaruga Howard to conduct it. As one of our rituals, the groups provide an important space to think together in a way that challenges the individualistic way we have become accustomed to in the Western culture.

Foulkes (the founder of group analysis) recognised the deeply social nature of the human personality, claiming that "the individual cannot be separated from the social context which defines him or her" (as cited in Brown \& Zinkin, 1994, p. 1). He defined the matrix as the "hypothetical web of communication and relationship in a given group" (Foulkes, 1964, p. 292). He also said that it was a common communication ground which is shared (Foulkes, 1990). The idea of the matrix has been split into two entities: the foundation matrix and the dynamic matrix. The foundation matrix is our common humanity, physiology, anatomy, and racial origins. It exists before the group even starts and is relatively static and unalterable (Foulkes, 1971). Dalal (1998) called it Mother Nature in disguise! The foundation matrix is our humanity, and the reality of being alive in the 21st century in New Zealand. It is useful to consider how difficult it is to access the foundational matrix for it is so deeply embedded in our unconscious as to be almost always inaccessible. If there is anywhere it can be noticed, it is in the large group where the complexity of our similarities and differences can become visible. Perhaps.

The dynamic matrix is what we create together, how we join and how we separate ourselves from each other, the lens through which each one of us sees the world and how that is mediated in the large group. In terms of the 2016 conference, the dynamic matrix is more accessible as it is what we created together in the large and small groups.

Another way I have come to think about the dynamic matrix is the web of communication that is created through "habitus", a word coined by Bourdieu (n.d.) to mean the social process that leads to patterns of behaviour and thinking that are enduring and transferable from one context to another. Habitus is formed through the interaction between the structures we live in and our experience. It is like a suit of clothing that we wear to fit our context. It is automatic, not thought about. Implicit in thinking about habitus is to recognise that we use our habitus as a source of power or not. So it helps me to be curious about how that was evident in the large group. There was a myriad of differences to hold in the large group: Māori - tau iwi - Pākehā, female - male, those who know (the stories, each other) - those who do not, those who enter the organisation through the old traditional pathway - those who enter through government registration; training orientation, choosing to be registered as psychotherapists or not; those who work in the public sector - those who work in the private sector. The list is endless. All these binaries were present; some were figure and others ground. However, they all influenced what was said and what was not said, and who spoke.

Who speaks, and can speak, what can be spoken in the group and what can only be spoken in private. My impression was that (in terms of proportions present) men spoke more than women, Māori spoke more than non-Māori; Māori voices and male voices could be heard more clearly than female voices. I wonder what impact this had on what happened in the group. There was a moment in the group when a local person spoke of what happens when 
people take their speaking out of the hui into the marae àtea (i.e. outside the meeting or group), and how it diminishes what is possible in the hui. I was reminded of something I often say in small groups at Auckland University of Technology: people are seeing each other every day so how do we hold the process of the group with integrity. I say it is like a bucket with holes in it if the group process just goes out. Our task then is to bring the group process back in. Sometimes it is very helpful to have conversations outside the group to clarify one's thoughts - they can then come back in. On the other hand, there is the boundary around what is public and what is private. If nine years ago in Napier, I had spoken privately to kaumātua: What would have happened? Perhaps a different eruption, perhaps nothing. It may have prevented a lot of pain. And yet we heard in the large group what we have gained from our prior experience in Napier.

In the second session a senior therapist spoke respectfully to another senior therapist about her fear and how she was not able to learn through being told off. She was joined by a couple of others. I kept a close eye on how this was being received. Another voice told of her own shame in response to the teaching words of the kuia, and that she realised her shame was part of an old pattern, and how she was able to shift out of her shame by taking responsibility for her mistake, for her disrespect in relation to Māori. She named this process of transmutation as key in opening space for a real partnership between Pākehā and Māori, enabling each of us to stand in our fullness alongside each other. I was pleased to see that our large group was able to lovingly hold both people in this exchange with a graceful acknowledgement through the singing of a waiata. This process was on the edge of what is (perhaps unconsciously) acceptable in a large group in our association. In the large group format it is of course useful and natural for this kind of conflict to come out, but when it is between the colonisers and the colonised, it has an increased sensitivity. I was thankful for the comment on the first day from a Māori voice saying, "You are quiet because you are thinking of the impact of your words on us. We don't mind a bit of stoush."

In my role I do not expect any particular topic to be discussed. I only intervene when I see the group has stopped thinking. An example of that was when the group was pressuring one group member, trying to get her to say what her pain was about: I suggested that we were focusing on her story of difficult interpersonal exchanges to avoid our own, and perhaps staying away from something in the group. We were confronted with what stories can and cannot be told in the large group space. Do we just shut something down in ourselves to manage these? Or what do we do?

At the end of the large group I felt a huge release of energy in my body. The woman next to me said, "I felt your energy, you were really present to the group, holding it, I could feel it." I was thankful for this comment over the next few days as the group stayed with me and I processed my experience and unravelled what I was left with.

\section{Discussion}

The themes that seem to be present in most of these reflections are bicultural diversity; holding as a way of facilitating openness and connectedness; spirituality, its presence and absence; time and space as restrictions and expansions and perhaps contributing to chaos, and manaakitanga as a core value for the conference committee. 
As Crea said, "Holding open space". The empathic facilitation by the small group conductors offered the possibility of being held. We were physically held by Te Ara o Tâwhaki with the beautiful marae attea and the bountiful food. The conference committee held us through their manaakitanga and I through my holding of the small group leaders, the committee, and the large group: Holding rather than leading. Holding is physical and emotional and contextual. Time was a feature of holding for me and, I think, for the small group conductors too. We had to hold time for the conference delegates to enable people to attend the events following the small and large groups. This created a boundary around the space provided. The emotional holding cannot be measured or even quite articulated, only felt.

The group facilitators and I have written this piece through a back and forth process. One of the issues that arose was about naming people. I am aware that there is a tradition in group analysis that the large group is a social space and therefore not subject to the usual rules of confidentiality. I believe it is more respectful not to name people. In the end we settled on naming only the keynote speakers who spoke in a public space.

Manaakitanga was the focus of Jules Morgaine's piece of writing above and reminds us of the huge task the committee took on and that no matter how carefully prepared a committee is, the map is not the territory. The committee was faced with forgetting to care for themselves as they stretched themselves to meet the needs of the living conference. This reminds me of the 2004 conference in Auckland where the food was eaten by latecomers who were ignorant of Māori protocol, while the pōwhiri continued. Out of the shame of this was born Ngā Ao E Rua, a group of psychotherapists who are committed to supporting and implementing the kaupapa of the Treaty of Waitangi for psychotherapy practice.

The efforts of the committee to create a bicultural conference by situating the conference at Te Ara o Tāwhaki and the gracious presence of Ngāti Kahungunu facilitated an opportunity for NZAP members to be with our Māori colleagues in a more robust way. The conference timetable was overflowing with opportunities for connection in different ways which leant itself to an experience of chaos and overwhelm at times. I think this also reflects the complexity of the group matrix as "process that is continuously replicating and potentially transforming patterns of intersubjective narrative themes that organise the experience of being together" (Stacey, 2001, p. 235). In other words, there was a lot to take in and mediate, more than could be consciously processed. This means we need time and space to reflect. For me reflection is part of who I am in the world, what I have learned as a psychotherapist that has leaked into everything I do (well almost).

This brings me to spirituality, a central and abiding theme from the conference. In his keynote address, David Tacey said that spirituality is, in essence, meaning making. As Amanda reminds us above, our history is a part of us and needs to be re-membered. I noticed at this conference a real difference in the way Māori and Pākehā behaved towards elders. I notice the way I and others here describe what I think are the rituals that reflect our spirituality. Are we being defensive? Is it too hard to bear if we consider that we have not yet found our spirituality except through Māori in this organisation? I am not sure. I hope this conversation will continue.

I leave the last word to Lynne who wrote the following after I sent the first draft of this article to the small group facilitators. 
The way I see it both Māori and Pākehā psychotherapy cultures are striving beautifully to express themselves further with more intensity and extensity within our association. It is really important for both voices to be heard, in the large groups, in the forum and newsletters and Ata. I feel certain that we can learn so much from each other especially in the conversations that bring affect and conflicts. If we try to avoid hurting each other by not expressing our views powerfully and not talking about our differences, we deprive ourselves of our real relationship and replace it with a phoney one.

A vital, maturing and growing association has to find a way to live with difference. Can we bring into association the many voices, listen to "difficult people" who disagree with us? I think it’s also important that Pākehā voices can speak freely in any environment we hold meetings and that Māori voices are listened to with respect. I actually think this is more in tune with tikanga Māori than a cleaned-up and conflict-repressed association that gives lip service to biculturalism while retaining members within the ranks who quietly and resentfully disagree with decisions and with processes. I guess, in summary, I think the value of freedom of speech is very important to our association's vitality along with the presence, which I don't doubt, of our capacity to hurt and heal, to separate and to come back together with love.

\section{References}

Bourdieu. (n.d.). Retrieved from http://www.powercube.net/other-forms-of-power/bourdieu-andhabitus/

Brown, D., \& Zinkin, L. (Eds.). (1994). The psyche and the social world. London, UK: Jessica Kingsley.

Cordery, S. (Director and producer). (2014). Notes to eternity [Motion picture]. Auckland, Aotearoa New Zealand.

Dalal, F. (1998). Taking the group seriously: Towards a post-Foulksian group analytic therapy (Vol.5). London, UK: Jessica Kingsley.

Foulkes, E. (Ed.) (1990). Selected papers of S. H. Foulkes: Psychoanalysis and group analysis. London, UK: Karnac.

Foulkes, S. H. (1971). Access to unconscious processes in the group-analytic group. Group Analysis, 4, 4-14.

Foulkes, S. H. (1964). Therapeutic group analysis. London, UK: Allen and Unwin.

Iti, T. (2015, June). Tama Iti: Mana: The power in knowing who you are [Video File]. Retrieved from https://www.youtube.com/watch?v=qeK3SkxrZRI

Mosse, J., \& Roberts, V. Z. (1994). Finding a voice: Differentiation, representation and empowerment in organisations under threat. In A. Obholzer \& V.Z. Roberts (Eds.), The unconscious at work (pp.147-155). London, UK: Routledge.

Stacey, R. (2001). Complexity and the group matrix. Group Analysis, 34(2), 221-239.

Visceral (1978). In Little, W., Fowler, H. F., \& Coulson, J. (Eds.), The shorter Oxford dictionary (3rd ed., vol. 2), p. 2481. Oxford, UK: Clarendon Press. 


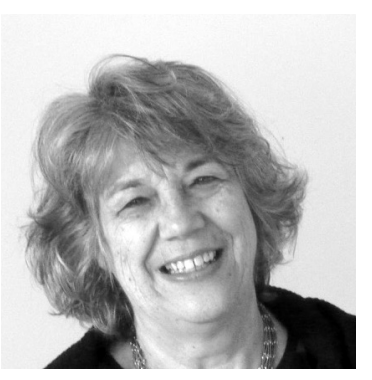

Margot Solomon is Head of Discipline (Psychotherapy) and a senior lecturer at Auckland University of Technology University, Auckland, New Zealand. She teaches postgraduate courses in advanced psychotherapy practice, clinical supervision, and group psychotherapy. Her small private practice includes individual psychoanalytic psychotherapy, supervision, and group psychotherapy. Contact details: msolomon@aut.ac.nz .

Virginia Edmond is a psychotherapist in private practice in Wellington. Her first career was as a teacher, mostly of English as a second language. She has been a trainer of psychotherapists and editor of a counselling and psychotherapy journal. She works with adults, couples, groups, and does supervision. Contact details: virginia.edmond@xtra.co.nz .

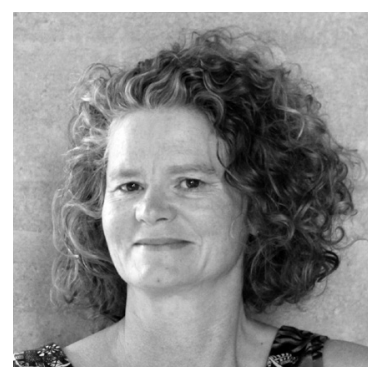

Amanda Garland was born in

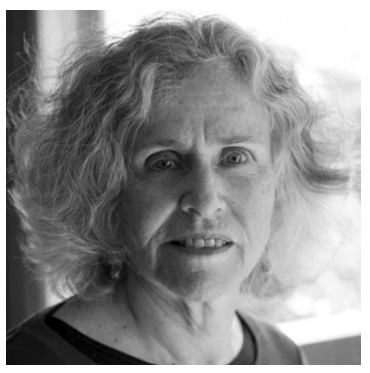
New Zealand and educated in London. She completed a training in art psychotherapy in 1988 at Goldsmith's College, the introductory course in group analysis at the Institute of Group Analysis in 1991, the understanding trauma course at the Tavistock and Portman Clinic in 2005, and a certificate in supervision at the Society of Analytic Supervision in London in 2007-2008. Amanda has worked for 27 years in mental health, psychiatry, and therapeutic community settings, as well as in private practice. Amanda is currently living and working in West Auckland. Alongside her art psychotherapy practice, she is engaged in educational work in co-housing and natural building, including group processes in intentional communities. Contact details: amanda.garland@gmail.com .

Lynne Holdem recently walked to Parihaka with Mayor Judd and others wanting a new conversation about justice and peace. Conference themes were echoed in talks along the way: healing and spirituality, guilt and reparation, the need to face uncomfortable truths and forge forgiving friendships. Alongside her private practice, Lynne works with Supporting Families in Mental Illness and is currently developing A Circle of Security attachment-based intervention for parents and children who live in the presence of mental illness and addiction. Lynne

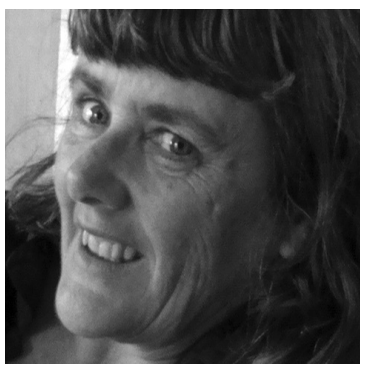
shares the NZAP children's issues portfolio with Judith Morris. Contact details: lynneholdem@ gmail.com . 


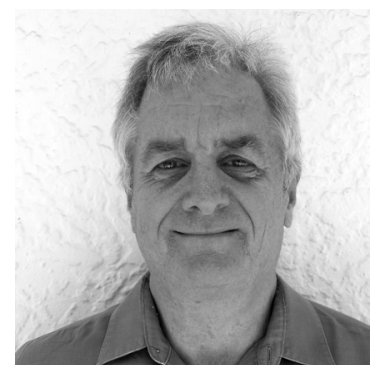

Burke Hunter loves being a psychotherapist. He became a member of NZAP in 1992. From the very start he was actively involved in the life of the Association at all levels. Conferences, for him, have been primarily a way to connect with others both professionally and as friends. As a psychotherapist, he values the connection that forms within the therapeutic relationship and the moments of growth and stillness that arrive sometimes unexpectedly, what he calls magic. At the heart of good relationship is good communication. Contact details: susaburk1@ihug.co.nz.

Crea Land is a relational therapist and supervisor in Tamaki Makaurau, Aotearoa. Born in Virginia, USA, she is the grandchild of Eastern European immigrants. Crea facilitated personal development groups for many years before completing her Masters Degree in Health Science (Psychotherapy) at Auckland University of Technology where she now facilitates reflective groups for psychotherapy students. From 2008 until 2013 Crea was involved with a global initiative that regarded the weaving together of Indigenous wisdom and modern worldviews as

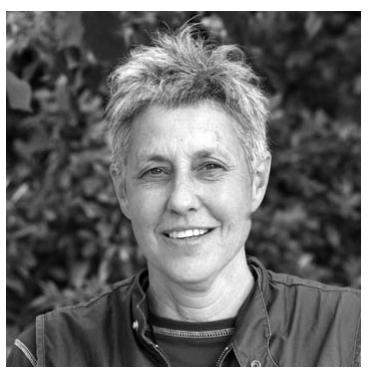
pivotal in bringing forth an environmentally sustainable, spiritually fulfilling, and socially just human presence on our planet. Therapeutically, Crea has a holistic approach as she invites in and works with the integration of mind, body, spirit and the environment. Contact details: crea@crealand.co.nz .

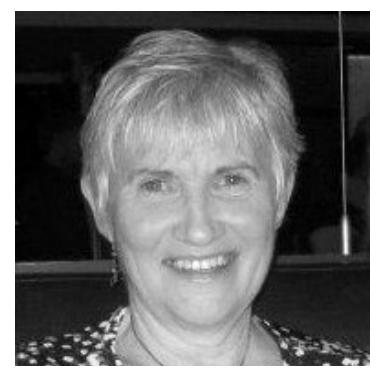

Fay Lilian's background is in social work and critical theories; her first psychotherapy training was in psychodrama and group dynamics. Much later in 2010 Fay gained a MHPrac (Psychotherapy Practice). In addition to her private practice, Fay provides therapy groups for Salvation Army clients, who are mostly Māori mothers with complex issues, and cofacilitates stopping violence groups for men. Fay has two adult daughters and a nearly-born mokopuna. Recently Fay was accepted by Waka Oranga as a provisional candidate to enter HAMACP pathway toward full membership of NZAP. Contact details: fay.lil@xtra.co.nz .

Jules Morgaine: Following seven years working as an occupational therapist in various mental health settings, then a further six years in a therapeutic community Jules began in private practice as a psychotherapist and supervisor in 1992.

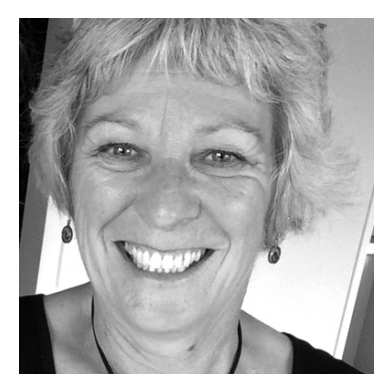


Alongside this she is a certified trainer of Hakomi Mindful Somatic Psychotherapy within Hakomi Institute (USA), leading trainings and facilitating workshops throughout Aotearoa and Australia. While maintaining a private practice three days per week at this point she has a strong passion for education and mentoring others in this challenging work of psychotherapy. Contact details: jmorgaine@xtra.co.nz .

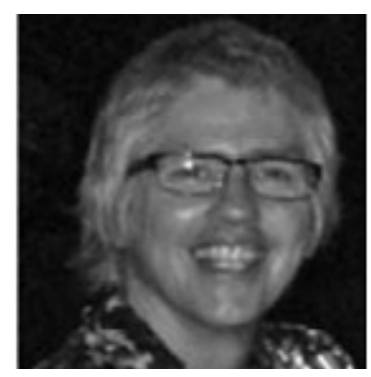

Claire Virtue is a psychotherapist based in Auckland. She trained with the Institute of Psychosynthesis and is a current staff member of the Institute. Claire co-facilitates process groups including a weekly psychotherapy group in Auckland with her long-time colleague Dale Wiren. She also facilitates group supervision with students and with post graduates. Contact details: the.claires@xtra.co.nz . 